\title{
Spectrum of Upper GI Endoscopy in Pediatric Population at a Tertiary Care Centre in Pakistan
}

\author{
Muhammad Rehan Khan', Shakeel Ahmed ${ }^{1,2^{*}}$, Syed Rehan Ali1, Prem Kumar Maheshwari1, \\ Muhammad Saad Jamal ${ }^{1}$ \\ ${ }^{1}$ Department of Pediatrics and Child Health, The Aga Khan University Hospital, Karachi, Pakistan \\ ${ }^{2}$ Department of Paediatrics, Medical \& Dental College, Bahria University, Islamabad, Pakistan \\ Email: ${ }^{*}$ shakeel.ahmed@aku.edu
}

Received 14 June 2014; revised 10 July 2014; accepted 5 August 2014

Copyright (C) 2014 by authors and Scientific Research Publishing Inc.

This work is licensed under the Creative Commons Attribution International License (CC BY).

http://creativecommons.org/licenses/by/4.0/

(c) (i) Open Access

\begin{abstract}
Although upper GI endoscopy is considered to be a gold standard in diagnosis of many pediatric gastrointestinal disorders, there is limited data about its utility from developing countries. We carried out this retrospective study at Aga khan University Hospital, Karachi, Pakistan from 20082012. During the study period, a total of 200 procedures were performed. Mean age of patients was 8.5 years. $66 \%$ of patients received general anesthesia for the procedure. Failure to thrive with suspected coeliac disease was the most common indication for the procedure, seen in $31 \%$ of patients. Gastritis was the most common abnormal endoscopic finding, seen in $14.5 \%$ of patients. Gastritis was the most common histopathological finding on biopsy, seen in $31 \%$ of the patients (n $=62)$. Findings were consistent with coeliac disease in $18 \%(n=36)$, duodenitis, $10.5 \%(n=21)$ and esophagitis, $4 \%(n=8)$ of patients. No immediate post procedure complication was noted in our study.
\end{abstract}

Keywords

Upper GI Endoscopy, Children, Indications

\section{Introduction}

Gastrointestinal diseases are an important healthcare problem worldwide, especially in pediatric age group [1]. Bozzini is considered to be the pioneer of modern gastroenterology, who used candle-powered lichtleiter for the first time in medical history in 1805 [2]. After the introduction of flexible endoscopy by Hirschowitz in 1950's, use of upper GI endoscopy also started in pediatrics [3]. This led to inception of field of pediatric gastroenterol-

\footnotetext{
*Corresponding author.

How to cite this paper: Khan, M.R., et al. (2014) Spectrum of Upper GI Endoscopy in Pediatric Population at a Tertiary Care Centre in Pakistan. Open Journal of Pediatrics, 4, 180-184. http://dx.doi.org/10.4236/ojped.2014.43025
} 
ogy in 1960's in developed countries [4]. Later on, fiberoptic endoscopies for children were developed mainly in 1970's and upper GI endoscopy became a standard of care in diagnosis of many gastrointestinal problems in children [5]-[7]. Since then, pediatric gastroenterology is growing rapidly and has emerged as one the most diverse medical-surgical sub-specialty in modern medicine in the developed world [8].

Despite the high diagnostic yield, upper GI endoscopy is still an under-utilized tool and information regarding its efficacy is scanty in most of the developing countries [9]. This is mainly due to lack of awareness about the role of this important diagnostic modality in children which prevents referrals of these children to a center where this facility is available. On the other hand, factors like lack of trained pediatric gastroenterologists or lack of well-equipped pediatric endoscopic suites in resource-limited countries may also play an important role. Furthermore, there is lack of data from nonwestern countries regarding the appropriate indications of endoscopy in children or while referring a child for endoscopy [8]. Therefore, we carried out this hospital-based study to report the common indications, endoscopic/histopathological findings and complications of pediatric upper GI endoscopy in our setup to increase awareness amongst pediatricians.

\section{Materials \& Methods}

The study was carried out in the Department of Paediatrics and Child Health at Aga Khan University Hospital, Karachi, Pakistan. Our hospital is a tertiary care referral center with well-equipped and advanced endoscopy suite. The medical records of all patients under the age of 15 years, who underwent upper GI endoscopy, from January 2008 to December 2012, were reviewed retrospectively using the electronic database system of our hospital. All of the pediatric patients in which upper GI endoscopy was performed during the study period were included in the study. The need for endoscopy was decided by general pediatricians. All pediatric upper GI endoscopies were performed by trained pediatric gastroenterologists/hepatologists. Informed consent was taken from parents/patients for the procedure after careful explanation of procedure details and potential complications. Mode of anesthesia was decided by gastroenterologists depending upon patient age, level of cooperation and physicians comfort level. Endoscopic findings were documented for each patient and biopsy materials for histopathology were taken. Patients were kept in recovery room to look for immediate post procedure complications related to procedure. Patients' demographic data including age, sex, and length of hospital stay were recorded. For the purpose of analysis, patients were divided into three age groups. Indications for upper GI endoscopy were recorded for each patient. Patients having height/weight below $5^{\text {th }}$ percentile with suspected coeliac disease were labeled as failure to thrive. Mode of anesthesia, complications of procedure and histopathological findings of biopsied materials were recorded. Wherever available, findings of serologic tests were also analyzed to see their correlation with the histopathological findings. The collected data was entered into the SPSS (statistical package for social science) Version 18.0 and analyzed through its statistical program. The frequencies of various indications, endoscopic findings, and histopathological findings for upper GI endoscopy were calculated.

\section{Results}

During the study period, a total of 200 patients underwent upper GI endoscopy and biopsy. Mean age of patients was 8.5 years with range of 2 months to 15 years. Older children (aged $10-15$ years) had highest frequency of upper GI endoscopy, i.e. $40 \%(n=80)$, followed by youngest children $(0-5$ years of age), in which frequency of endoscopy was 32\% $(n=63)$. The frequency of endoscopy in children between $5-10$ years of age was $28 \%$ $(n=56)$. Around two thirds of the children $(66 \%)$ were given general anesthesia for the procedure while in remaining only sedation was required. No immediate post procedure complications were noted in any of the patients during the file review. Failure to thrive with suspected coeliac disease was the most common indication for the procedure, seen in $31 \%$ patients $(n=62)$. Table 1 describes the frequency of various indications for upper GI endoscopy in our study. In almost half of the patients $(46 \%, n=92)$, the endoscopic findings were normal and about one third of the patients $(n=61)$ had nonspecific endoscopic findings. Gastritis was the most common abnormal endoscopic finding, seen in 14.5\% $(n=29)$ of patients. Table 2 describes the details of endoscopic findings in study. Gastritis was the most common histopathological finding on biopsy, seen $31 \%(n=62)$. Findings were consistent with coeliac disease in $18 \%(n=36)$, duodenitis, $10.5 \%(n=21)$ and esophagitis, $4 \%(n=8)$ of patients. Around 7.5\% ( $\mathrm{n}=15)$ of patients had nonspecific findings and 15.5\% $(\mathrm{n}=31)$ had normal histopathological findings. No biopsy/histopathology was done in 27 patients. Serological tests for coeliac disease were found positive in 37 patients before endoscopy. Out of these, $78 \%(n=29)$ had pathological confirmation of disease on biopsy. 
Table 1. Indications of upper GI endoscopy in children.

\begin{tabular}{ccc}
\hline Indication & Number & $\%$ age \\
\hline Failure to Thrive (Suspected Coeliac Disease) & 62 & 31 \\
Recurrent Abdominal Pain & 37 & 18.5 \\
Upper GI Bleeding & 30 & 15 \\
Chronic Vomiting & 24 & 12 \\
Chronic Diarrhea & 20 & 10 \\
Dysphagia & 12 & 6 \\
Hepatosplenomegaly & 12 & 6 \\
\hline
\end{tabular}

Table 2. Endoscopic findings.

\begin{tabular}{ccc}
\hline Finding & Number & \% age \\
\hline Normal & 92 & 46 \\
Non-Specific Findings & 61 & 30.5 \\
Gastritis & 29 & 14.5 \\
Esophageal Varices & 10 & 5 \\
Esophagitis & 5 & 2.5 \\
Gastroduodenal Ulcer & 3 & 1.5 \\
\hline
\end{tabular}

\section{Discussion}

Upper GI endoscopy is one of the most specific, quick and cost effective diagnostic tool for a wide variety of gastrointestinal disorders in children, especially under the circumstances when other investigations are not conclusive. In addition to its diagnostic use, upper GI endoscopy also has an established therapeutic role and various disorders like upper GI bleeding, Mallory Weiss tear; gastric erosions can be effectively treated by endoscopy [10] [11]. Therefore, despite changing indications over a period of time, the disorders requiring upper GI endoscopy for diagnostic or therapeutic purposes in children have shown a rising trend [12].

In literature from most of the developing countries, recurrent abdominal pain has been reported as the commonest indication of upper GI endoscopy. In various reports, this frequency of abdominal pain is reported to be ranging from $8 \%$ to $43 \%$ [13]-[15]. In our study, the frequency of abdominal pain as an indication of upper GI endoscopy was $18.5 \%$. So our results are comparable to other reports from developing countries. However, the most common indication of upper GI endoscopy in our study was failure to thrive (suspected coeliac disease), seen in $31 \%$ of children. No such finding is reported in literature from other developing countries. However, in a study from France, Jantchou et al, have reported a similar trend, where failure to thrive was the highest indication for performing upper GI endoscopy [16].

Similarly, almost half of the children (46\%) who underwent upper GI endoscopy in our study had normal endoscopic findings while about one third (30.5\%) of the patients had non-specific findings. Thus, endoscopic diagnosis was established in only one quarter of patients. Similar trends have been noted in other studies as well, where almost half of the endoscopies were normal [13] [14] [17]. Gastritis was the most common endoscopic finding in our study, seen in $14.5 \%$ of children. Similar reports have been shown in other studies as well.

Although, this procedure is safe and can be performed even without sedation or anesthesia in adult patients, there are no specific guidelines for pediatric age group in this regard. Even in latest consensus guidelines developed by Canadian association of gastroenterology, the concerns have been raised regarding sedation/anesthesia in children [18]. Although un-sedated procedure can be cost effective and time saving [19], in our study about $2 / 3$ of the endoscopies were performed under general anesthesia. Approximately $60 \%$ of the upper GI related complications are secondary to sedatives/analgesic agents which can lead to cardiopulmonary compromise [20]. No immediate post procedure complications were noted in our study. However, there is need to develop guidelines for sedation in children not only to save resources but also to prevent unnecessary exposure to seda- 
tive/anesthetic agents which can be hazardous for children.

\section{Conclusion}

Upper GI endoscopy is a safe procedure in children. The awareness about its diagnostic and therapeutic role should be raised amongst pediatricians in developing countries. There is also a need to develop training programs of pediatric gastroenterology and pediatric endoscopic suites in developing countries so that children may benefit from this state of the art diagnostic modality.

\section{Competing Interest}

None.

\section{Funding}

None.

\section{References}

[1] El-Mouzan, M.I., Abdullah, A.M., Al-Sanie, A.M., et al. (2001) Pattern of Gastro Esophageal Reflux in Children. Saudi Medical Journal, 22, 419-422.

[2] Sircus, W. (2003) Milestones in the Evolution of Endoscopy: A Short History. Journal of the Royal College of Physicians of Edinburgh, 33, 124-134.

[3] Haight, M. and Thomas, D.W. (1995) Pediatric Gastrointestinal Endoscopy. Gastroenterologist, 3, 181-186.

[4] Franciosi, J.P., Fiorino, K., Ruchelli, E., et al. (2010) Changing Indications for Upper Endoscopy in Children during a 20-Year Period. Journal of Pediatric Gastroenterology \& Nutrition, 51, 443-447. http://dx.doi.org/10.1097/MPG.0b013e3181d67bee

[5] Papp, J.P. (1973) Endoscopic Experience in 100 Consecutive Cases with the Olympus GIG Endoscope. The American Journal of Gastroenterology, 60, 466-472.

[6] Gleason, W.A., Tedesco, F.J., Keating, J.P., et al. (1974) Fiber Optic Gastrointestinal Endoscopy in Infants and Children. The Journal of Pediatrics, 85, 810-813. http://dx.doi.org/10.1016/S0022-3476(74)80347-1

[7] Graham, D.Y., Klish, W.J., Ferry, G.D., et al. (1978) Value of Fiber Optic Gastrointestinal Endoscopy in Infants and Children. Saudi Medical Journal, 71, 558-560. http://dx.doi.org/10.1097/00007611-197805000-00022

[8] Ginger, M.A. (2001) Gastroenterologic Endoscopy in Children: Past, Present and Future. Current Opinion in Pediatric, 13, 429-434. http://dx.doi.org/10.1097/00008480-200110000-00008

[9] Okello, T.R. (2006) Upper Gastrointestinal Endoscopic Findings in Adolescents at Lacor Hospital, Uganda. African Health Sciences, 6, 39-42.

[10] El-Mouzan, M.I., Al-Mofleh, I.A., Abdullah, A.M., et al. (2004) Indications and Yield of Upper Gastrointestinal Endoscopy in Children. Saudi Medical Journal, 25, 1223-1225.

[11] Aduful, H., Naaeder, S., Darko, R., et al. (2007) Upper Gastrointestinal Endoscopy at the Korle Bu Teaching Hospital, Accra, Ghana. Ghana Medical Journal, 41, 12-16.

[12] Murray, J.A., Van Dyke, C., Plevak, M.F., et al. (2003) Trends in the Identification and Clinical Features of Celiac Disease in a North American Community, 1950-2001. Clinical Gastroenterology and Hepatology, 1, $19-27$. http://dx.doi.org/10.1053/jcgh.2003.50004

[13] Joshi, M.R., Sharma, S.K. and Baral, M.R. (2005) Upper GI Endoscopy in Children- in an Adult Suite. Kathmandu University Medical Journal (KUMJ), 3, 111-114.

[14] Mudawi, H.M., El Tahir, M.A., Suleiman, S.H., et al. (2009) Paediatric Gastrointestinal Endoscopy: Experience in a Sudanese University Hospital. Eastern Mediterranean Health Journal, 15, 1027-1031.

[15] Hafeez, A., Ali, S. and Hassan, M. (2000) An Audit of Pediatric Upper Gastrointestinal Endoscopies. Journal of the College of Physicians and Surgeons Pakistan, 10, 13-15.

[16] Jantchou, P., Schirrer, J. and Bocquet, A. (2007) Appropriateness of Upper Gastrointestinal Endoscopy in Children: A Retrospective Study. Journal of Pediatric Gastroenterology and Nutrition, 44, 440-445. http://dx.doi.org/10.1097/MPG.0b013e31802c6847

[17] Quine, M.A., Bell, G.D., McCloy, R.F., et al. (1994) Appropriate Use of Upper Gastrointestinal Endoscopy-A Prospective Audit. Steering Group of the Upper Gastrointestinal Endoscopy Audit Committee. Gut, 35, 1209-1214. 
http://dx.doi.org/10.1136/gut.35.9.1209

[18] Bishop, P.R., Nowicki, M.J., May, W.L., et al. (2002) Unsedated Upper Endoscopy in Children. Gastrointestinal Endoscopy, 55, 624-630. http://dx.doi.org/10.1067/mge.2002.123417

[19] Armstrong, D., Barkun, A., Bridges, R., et al. (2012) Canadian Association of Gastroenterology Consensus Guidelines on Safety and Quality Indicators in Endoscopy. Canadian Journal of Gastroenterology, 26, 17-31.

[20] ASGE Standards of Practice Committee, Ben-Menachem, T., Decker, G.A., et al. (2012) Adverse Events of Upper GI Endoscopy. Gastrointestinal Endoscopy, 76, 707-718. http://dx.doi.org/10.1016/j.gie.2012.03.252 
Scientific Research Publishing (SCIRP) is one of the largest Open Access journal publishers. It is currently publishing more than 200 open access, online, peer-reviewed journals covering a wide range of academic disciplines. SCIRP serves the worldwide academic communities and contributes to the progress and application of science with its publication.

Other selected journals from SCIRP are listed as below. Submit your manuscript to us via either submit@scirp.org or Online Submission Portal.
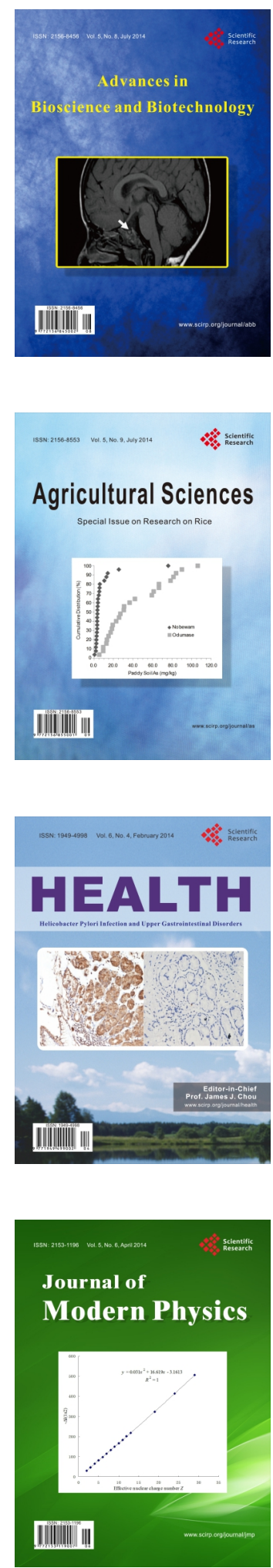
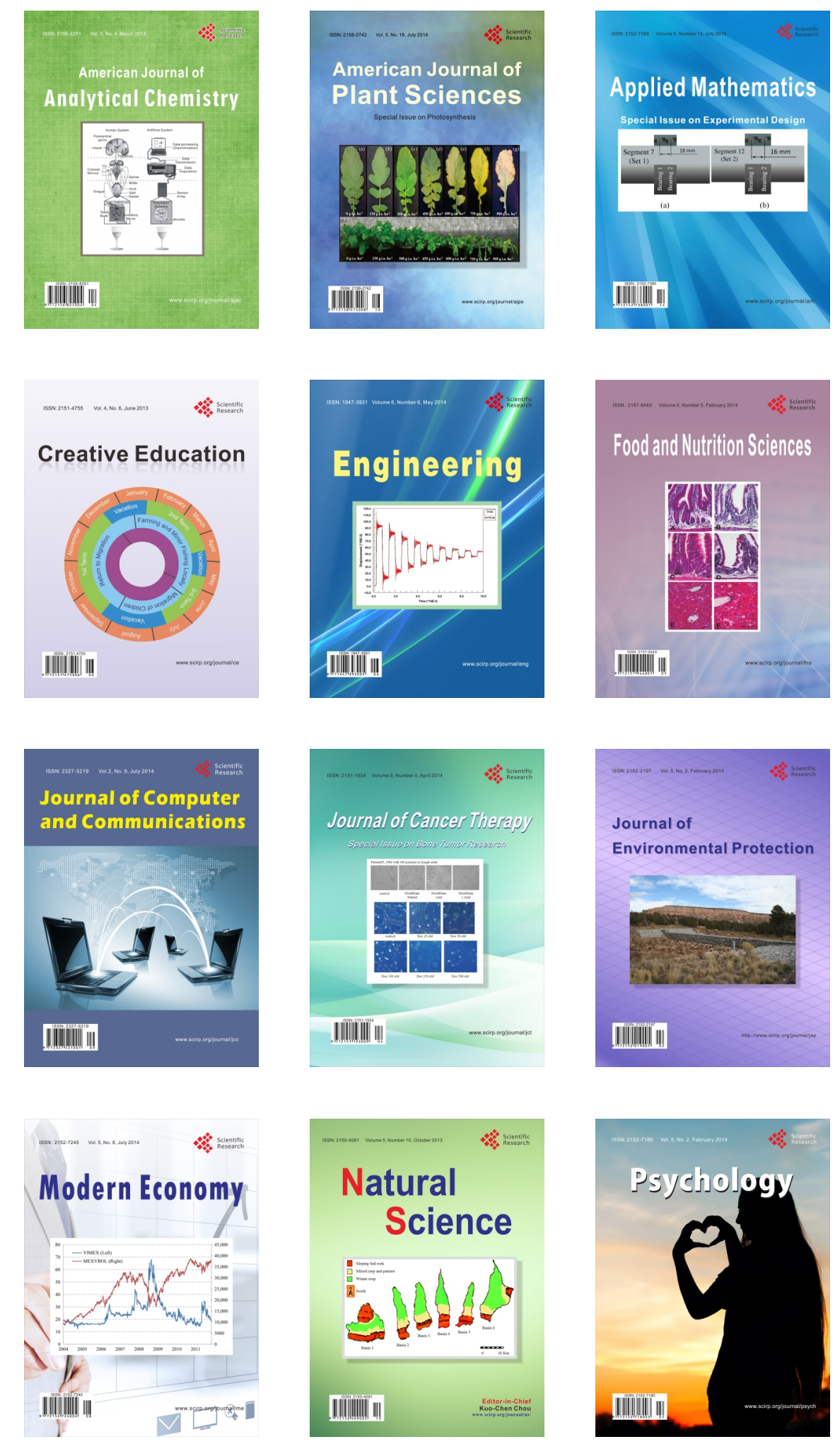